\title{
AS DIFICULDADES DE SE GARANTIR UMA ESCOLHA RACIONAL E CONSCIENTE DO CONSUMIDOR NA SOCIEDADE DA INFORMAÇÃO
}

\section{Danúbia Paiva ${ }^{1}$}

\section{Resumo:}

$\mathrm{O}$ artigo visa analisar se as novas práticas comerciais desenvolvidas na sociedade da informação observam a legislação de consumo vigente, principalmente diante do comércio eletrônico e das novas relações jurídicas obrigacionais. O trabalho considerou o método hipotético dedutivo para realização da pesquisa, com foco nas novas perspectivas do Direito Privado. A partir do presente estudo, extraíram-se algumas considerações com o objetivo de trazer maior segurança jurídica às relações consumeristas, atualmente baseadas na personalização de produtos ao consumidor.

Palavras-chave: Sociedade da informação; Consumidor; Práticas comerciais; Direito Privado; Século XXI

\section{THE DIFFICULTIES OF ENSURING A CONSUMER'S RATIONAL AND CONSCIENT CHOICE IN THE INFORMATION SOCIETY}

\begin{abstract}
:
The article aims to analyze whether the new commercial practices developed in the information society comply with the current consumer legislation, mainly in the face of electronic commerce and the new mandatory legal relations. The work considered the hypothetical deductive method for conducting the research, focusing on the new perspectives of Private Law. From this study, some considerations were extracted in order to bring greater legal certainty to consumer relations, currently based on the personalization of products to the consumer.
\end{abstract}

Keywords: Information society; Consumer; Commercial practices; Private right; XXI Century

\section{INTRODUÇÃO}

O presente trabalho discorre sobre as novas práticas comerciais desenvolvidas na sociedade da informação.

Há algum tempo se sente o impacto da tecnologia e da inovação no cotidiano. A revolução digital, iniciada na década de 1960, foi o ponto de partida para diversas

\footnotetext{
${ }^{1}$ Advogada e Professora do Programa de Mestrado e da Graduação da Universidade Fumec. Doutora em Direito Processual Civil pela Universidade PUC/MINAS (2020). Mestre em Direito Público pela Universidade FUMEC (2015). Graduada em Direito pela UFMG (2007) e em Gestão Pública e Direito Administrativo pelo UNI/BH (2004). Possui Pós-graduação Lato Sensu em Direito Processual Civil pela UNIDERP (2010) e em Direito do Estado pela Universidade Cândido Mendes (2019) (http://lattes.cnpq.br/5839057345626036).
} 
transformações sociais.

Desde então, essas transformações trouxeram importantes alterações nas relações sociais e comerciais. Ocorreu uma ampliação significativa de conflitos, de experiências, de relações jurídicas, de serviços, de produtos e de discussões, sobretudo após o surgimento da Internet, que fez nascer uma sociedade "hiperconectada".

Nesse cenário, deve-se lembrar que o Direito é o reflexo da vida humana e das suas relações.

Por tal razão, quando os sistemas sociais, políticos, econômicos e culturais se transformam, surgem novas demandas e "crises" que precisam ser devidamente regulamentadas pelo ordenamento jurídico, bem como efetivamente solucionadas pelo Judiciário, caso acionado.

Portanto, diante de uma alteração significativa dos usos e dos costumes, de uma mudança cultural e comportamental nos mais variados setores, não há dúvida de que grande parte das preocupações dessa "sociedade digitalizada" irá trazer à tona importantes discussões acerca de direitos, como os da privacidade, liberdade, igualdade, segurança, propriedade, livre iniciativa, livre concorrência, informação, valorização do trabalho, e, principalmente, em relação à preservação da dignidade da pessoa humana.

Assim, na medida em que se amplia o alcance dessa "cultura virtual", verificada desde o advento da rede mundial de computadores, e se alteram as relações sociais pela tecnologia, o Direito necessita cada vez mais ser (re)pensado e (re)estruturado, a fim de se adequar a essa nova realidade.

Em um primeiro momento, o enfoque é analisar a compatibilidade entre o Direito e as novas relações jurídicas provenientes do uso da tecnologia. Em relação ao Direito do Consumidor, importa verificar se essas relações jurídicas estão se desenvolvendo observando a legislação de consumo vigente, principalmente diante do comércio eletrônico e da popularização das plataformas digitais.

Atualmente, são diversos modelos de negócios de intermediação de produtos e serviços, não havendo dúvida quando à capacidade das plataformas digitais de oferecerem praticidade, rapidez, e atendimento de qualidade.

Contudo, de acordo com a História, a industrialização e a expansão das relações do mercado de consumo só vieram a intensificar a fragilidade do consumidor. Assim, "discurso da eficiência" não pode (novamente) ocultar o abandono das garantias e dos 
direitos dos consumidores.

Diante dessas questões, este artigo busca abordar conceitos básicos da relação de consumo para, em seguida, apresentar algumas considerações sobre os possíveis problemas da "personalização" de produtos e serviços oferecidos ao consumidor.

O trabalho considerou o método hipotético dedutivo para realização da pesquisa, com foco nas novas perspectivas do Direito Privado. Seu objetivo é evitar que o grande avanço tecnológico observado nas últimas décadas gere mais dificuldades, impedindo ao consumidor uma escolha racional e consciente sobre o que o realmente deseja.

\section{A RELAÇÃO CONSUMERISTA}

É essencial para a aplicação das normas do Código de Defesa do Consumidor identificar, primeiramente, se há relação de consumo na transação comercial efetivada; isto é, se existe de um lado o fornecedor ou prestador de serviços e, de outro lado, o consumidor, definindo assim o campo de aplicação da norma consumerista.

À luz dessas considerações, é importante consignar os conceitos de consumidor e fornecedor, relevantes inclusive para se identificar a existência ou não da relação jurídica de consumo.

\subsection{O CONCEITO DE CONSUMIDOR}

É elementar que o conceito de consumidor derive, principalmente, da própria literalidade da lei, reforçada pelas doutrinas conceitualmente aceitas com a recepção e interpretação jurisprudencial.

De acordo com o art. $2^{\circ}$ da lei 8078, o Código de Defesa do Consumidor, consumidor é "toda pessoa física ou jurídica que adquire ou utiliza produto ou serviço como destinatário final" (BRASIL, 1990).

Amplia o código o conceito de consumidor quando estabelece, em seu parágrafo único, que se considera consumidor também todos aqueles que de alguma forma intervenham na relação de consumo (BRASIL, 1990).

$\mathrm{O}$ conceito geral de consumidor, estabelecido neste art. $2^{\circ}$, refere-se explicitamente à aquisição ou utilização em caráter final de um determinado bem, não contemplando como consumidores, genericamente, aqueles que adquirem o produto em fase 
intermediária, como os revendedores, ou apenas adquirem o produto para transformá-lo ou mesmo implementá-lo em outro.

Nada obstante essa conceituação genérica, este conceito pode ser modificado por determinação legal expressa, conforme ocorreu com o advento das previsões dos arts. 17 e 29 do CDC, sendo que, o primeiro, estendeu às vítimas do evento danoso a condição de consumidor, e o segundo, equiparou a esse todos os que forem expostos às práticas comerciais, à publicidade abusiva, aos danos decorrentes do seu uso, etc. (BRASIL, 1990).

Cláudia Lima Marques, aponta duas correntes doutrinárias que divergem quanto ao âmbito do conceito de consumidor, quais sejam, os finalistas e os maximalistas.

Para os finalistas, pioneiros do consumerismo, a definição de consumidor é o pilar que sustenta a tutela especial. Esta tutela só existe porque o consumidor é a parte vulnerável nas relações contratuais no mercado, como afirma o próprio CDC no art. $4^{\circ}$, inciso I. Logo, convém delimitar claramente quem merece esta tutela e quem não a necessita, quem é consumidor e quem não é. Propõem então que se interprete a expressão "destinatário final" do art. $2^{\circ}$ de maneira restrita, como requerem os princípios básicos do CDC, exposto nos arts. $4^{\circ}$ e $6^{\circ}$.

Destinatário final é aquele destinatário fático e econômico do bem ou serviço, seja ele pessoa jurídica ou física. Logo, segundo esta interpretação teleológica, não basta ser destinatário fático do produto, retirá-lo da cadeia de produção, levá-lo para o escritório ou residência, é necessário ser destinatário final econômico do bem, não adquiri-lo para revenda não adquiri-lo para uso profissional, pois o bem seria novamente um instrumento de produção cujo preço será incluído no preço final do profissional que o adquiriu. Neste caso não haveria a exigida "destinação final" do produto ou serviço. (...)

Já os maximalistas vêem nas normas do CDC o novo regulamento do mercado de consumo brasileiro, e não normas orientadas para proteger somente o consumidor não-profissional. O CDC seria um Código geral sobre o consumo, um Código para a sociedade de Consumo, o qual institui normas e princípios para todos os agentes do mercado, os quais podem assumir os papéis ora o papel de fornecedor, ora de 
consumidores. (MARQUES, 2002).

Mais adiante, conclui a autora:

(...) concordamos com a interpretação finalista das normas do CDC. A regra do art. $2^{\circ}$ deve ser interpretada de acordo com o sistema de tutela especial do Código e conforme a finalidade da norma, a qual vem determinada de maneira clara pelo art. $4^{\circ}$ do CDC. Só uma interpretação teleológica da norma do art. $2^{\circ}$ permitira definir quem são os consumidores no sistema do CDC. Mas além dos consumidores stricto sensu, conhece o CDC os consumidores-equiparados, os quais por determinação legal merecem a proteção especial de suas regras. Tratase de um sistema tutelar que prevê exceções em seu campo de aplicação sempre que a pessoa física ou jurídica preencher as qualidades objetivas de seu conceito e as qualidades subjetivas (vulnerabilidade), mesmo que não preencha a de destinatário final econômico do produto ou serviço. (MARQUES, 2002).

Assim, como ponderado pela professora Cláudia Lima Marques, o conceito de consumidor não deve ser entendido simplesmente como aquele que é o destinatário final do bem adquirido, mas sim aquele, pessoa física ou jurídica, que utiliza de produto ou serviço como bem de capital e que de alguma forma intervém na relação de consumo, adquirindo bens ou serviços destinados ao seu uso privado por pessoa que exerça, com caráter profissional, uma atividade econômica.

Outros dispositivos constantes do Código de Defesa do Consumidor, conforme retro ressaltado, estabelecem proteção também àqueles que não são destinatários finais dos produtos ou serviços. Eles não são os titulares absolutos do direito, mas são beneficiados pela abrangência da responsabilidade do fornecedor.

Alonga o conceito o art. 17 da legislação consumerista que, para efeito da seção - Da responsabilidade pelo Fato do Produto ou Serviço - equiparam-se aos consumidores todas as vítimas do evento danoso. Deve-se somar também o contido no art. 29 do Código de Defesa do Consumidor quanto às práticas comerciais onde o conceito de consumidor sofre nova ampliação (BRASIL, 1990).

Consigna-se que o art. 17 equiparou a vítima do acidente do consumo (pessoa que foi atingida pelo fato do produto/serviço) a consumidor, para os fins de 
responsabilizar o fornecedor do produto/serviço defeituoso de forma objetiva (BRASIL, 1990).

Nesse sentido Zelmo Denari informa que o CDC demonstra a preocupação com "terceiros" nas relações de consumo, protegendo os denominados bystanders, vale dizer, aquelas pessoas estranhas à relação de consumo, mas que sofreram prejuízo em razão dos defeitos intrínsecos ou extrínsecos do produto ou serviço (DENARI, 1998).

Antonio Hermam de Vasconcelos e Benjamin, comentando o dispositivo do art. 29 do Código de Defesa do Consumidor, conta que, a princípio, o conceito do art. 29 integrava o corpo do art. $2^{\circ}$ do CDC. Contudo, em função do lobby empresarial que queria retirá-lo por completo da lei, foi o mesmo transportado, por sugestão do próprio Antonio Herman, para o Capítulo V (BENJAMIN, 1998).

O art. 29 é uma disposição especial, que abre o capítulo V do Código sobre "Práticas Comerciais", aplicável, a todas as seções deste Capítulo. É apontado pela doutrina como uma tentativa do legislador reprimir os abusos do poder econômico, protegendo os interesses econômicos dos consumidores-finais, na medida em que os "consumidores-equiparados" combatam práticas comerciais abusivas que os lesam diretamente e que mediatamente, prejudicam os outros consumidores e a equilíbrio do mercado (BRASIL, 1990).

Cláudia Lima Marques, falando sobre este dispositivo, confirma essa tese:

O art. 29, supera, portanto, os estritos limites da definição jurídica de consumidor para imprimir uma definição de política-legislativa! Parece-nos que, para harmonizar os interesses presentes no mercado de consumo, para reprimir, para reprimir eficazmente os abusos do poder econômico, para proteger os interesses econômicos dos consumidoresfinais, o legislador concedeu um poderoso instrumento nas mãos daquelas pessoas (mesmo agentes econômicos) expostas às práticas abusivas. Estas, mesmo não sendo "consumidores stricto sensu", poderão utilizar das normas especiais do CDC, de seus princípios, de sua ética de responsabilidade social no mercado, de sua nova ordem pública, para combater as práticas comerciais abusivas! (MARQUES, 2002). 
Já Maria Zanardo leciona que o consumidor equiparado é também a pessoa que foi exibida a qualquer uma das práticas comerciais; isto é, técnicas as quais o fornecedor se utiliza para comercializar, vender, oferecer o seu produto ou serviço ao consumidor potencial, atingindo a quem se pretende transformar em destinatário final: o consumidor/adquirente. Pela sistemática adotada pelo CDC, abrange a expressão "práticas Comerciais" desde a oferta do produto até as cobranças de dívidas. Estende-se, pois, da pré-venda à pós-venda (DONATO, 1993).

Dito isso, passa-se no próximo item ao exame do conceito de fornecedor.

\subsection{O CONCEITO DE FORNECEDOR}

O conceito de fornecedor está bem explicitado no caput do art. $3^{\circ}$ da Lei 8.078/90 que diz:

Art. $3^{\circ}$ - Fornecedor é toda pessoa física ou jurídica, pública ou privada, nacional ou estrangeira, bem como os entes despersonalizados, que desenvolvem atividade de produção, montagem, criação, construção, transformação, importação, exportação, distribuição ou comercialização de produtos ou prestação de serviços (BRASIL, 1990).

A palavra atividade do art. $3^{\circ}$ traduz o significado de que todo produto ou serviço prestado deverá ser efetivado de maneira habitual, ou seja, de forma profissional ou comercial.

Os parágrafos $\S 1^{\circ}$ e $\S 2^{\circ}$ conceituam o que vem a ser produto e serviço, estabelecendo:

\footnotetext{
Art. $3^{\circ}(\ldots)$

$\S 1^{\circ}$ - Produto é qualquer bem móvel ou imóvel, material ou imaterial. $\$ 2^{\circ}$ - Serviço é qualquer atividade fornecida no mercado de consumo, mediante remuneração, inclusive as de natureza bancárias, financeiras, de crédito e securitária, salvo as decorrentes das relações de caráter trabalhista (BRASIL, 1990).
}

A conceituação de fornecedor não é tão polêmica quanto a de consumidor, tendo a doutrina tratado do assunto sem maiores disparidades.

Luiz Antonio Rizzato Nunes, ao comentar o art. $3^{\circ}$ do Código de Defesa do Consumidor, diz: 
O fornecedor é qualquer empresa, pessoa jurídica, civil ou comercial, nacional ou estrangeira. Estão enquadradas na previsão legal tanto as empresas privadas como as empresas públicas. Além disso, até mesmo uma pessoa física, uma pessoa natural, pode ser considerada fornecedora para os fins da lei. Para isso basta que ela se enquadre na descrição legal de alguém que exerça quaisquer atividades de produção, montagem, criação, transformação, importação, exportação, distribuição ou comercialização de produtos ou prestação de serviços. Exatamente da mesma forma como prescrito para as pessoas jurídicas (NUNES, 1991).

Assim, para o autor, fornecedor é todo aquele que exerce atividade no mercado de consumo mediante remuneração, sem qualquer distinção, cabendo salientar que é dispensável que o fornecedor seja uma pessoa jurídica, já que o art. $3^{\circ}$ autoriza inclusive a pessoas despersonalizadas.

Vale transcrever, ainda, outros conceitos elaborados a respeito de fornecedor, são eles: "Todo comerciante ou estabelecimento que abastece ou fornece habitualmente uma casa ou um outro estabelecimento dos gêneros e mercadorias necessários ao seu consumo" (PLÁCIDO E SILVA, 1973). "Fornecedor numa palavra é o fabricante, ou vendedor, ou prestador de serviços" (SAAD, p. 1991).

Feitas essas considerações, passa-se a seguir ao exame das possíveis dificuldades de se garantir uma escolha racional e consciente do consumidor na sociedade da informação.

\section{AS DIFICULDADES DE SE GARANTIR UMA ESCOLHA RACIONAL E CONSCIENTE DO CONSUMIDOR NA SOCIEDADE DA INFORMAÇÃO}

A elaboração do Código de Defesa do Consumidor se deu em virtude do mandamento constitucional expresso no inciso XXXII, do art. $5^{\circ}$ da Constituição da República, que estabelece que o Estado promoverá, na forma da lei, a defesa do consumidor (BRASIL, 1988).

De fato, a Constituição, ao elevar a defesa do consumidor à esfera constitucional de nosso ordenamento, incluindo-a entre os direitos e deveres individuais e coletivos, e, em um segundo momento, ao erigir a defesa do consumidor à categoria de princípio geral da atividade econômica (art. 170, V), produziu o relevante efeito de legitimar e promover as medidas de intervenção estatal necessárias a assegurar a proteção prevista constitucionalmente (BRASIL, 1988). 
Ademais, sua elaboração decorre também de uma antiga exigência da economia de mercado, que não possuía um meio adequado e competente para equilibrar a relação existente entre os consumidores e os fornecedores.

No Direito Brasileiro as relações privadas sempre foram regidas pelo Código Civil, inclusive as relações de consumo. Porém, depois da década de 30, referido código passou a perder seu caráter centralizador, porquanto adentraram no mundo jurídico uma série de outras leis extravagantes que, pela abrangência e especialidade, colocavam em xeque o papel absoluto e central do Código Civil de 1916 (BRASIL, 1916).

Entretanto, como já registrado, de acordo com a história, a industrialização e a expansão das relações do mercado de consumo só vieram a intensificar a fragilidade do consumidor.

Os fornecedores com a intenção de conseguirem novos consumidores criavam constantemente técnicas e procedimentos abusivos de venda de produtos e serviços de consumo.

A sofisticação dos métodos utilizados pelo marketing fez com que a publicidade prestasse ao consumidor cada vez menos informações sobre os produtos, induzindo-o a erro. Os contratos deixaram de ser discutidos entre os contratantes para serem impostos ao consumidor. Surgiram daí os "contratos de adesão" que, em geral, resultaram em diversas vantagens para os fornecedores em detrimento dos consumidores.

Verificou-se também que os inúmeros bens de consumo, em virtude de sua produção em série, passaram a apresentar vícios e defeitos, sendo muitas vezes impróprios ao uso do consumidor, ou ainda representando perigo à saúde e segurança deste.

Neste ponto, cumpre ressaltar que o grande avanço tecnológico observado nas últimas décadas no oferecimento de bens e serviços de consumo vêm gerando as mesmas dificuldades daquelas verificadas quando da intensificação da industrialização.

O "Big Data", que descreve não só a tecnologia apropriada para a captura de dados, como também o crescimento, a disponibilidade e o uso exponencial de informações estruturadas e não estruturadas que circulam pela Internet, tem gerado desequilíbrio, já que o consumidor está em posição mais vulnerável e mais exposto neste ambiente virtual.

Na verdade, o consumidor acaba se sujeitando a fornecer seus dados sem ter muita informação - muitas vezes sendo estes dados desnecessários para aquele tipo de transação 
comercial-, para que possa adquirir determinado produto ou serviço de um fornecedor.

Além disso, esta prática acaba por ser adotada para "facilitar" a escolha de produtos ou serviços que seriam "ideais" àquele consumidor, a fim de personalizar a oferta.

A existência dessas plataformas comerciais de base tecnológicas de geração, recepção e transmissão de dados que serão processados, analisados e transformados em algoritmos, é um fenômeno que funciona com base neste conceito de Big Data, a caracterizar a Quarta Revolução Industrial.

O uso dessa ferramenta, entretanto, deve ser vislumbrado com prudência e cautela. Não apenas diante da "utilidade" desses dados para a inteligência artificial, mas sobretudo quando o processamento trata de dados pessoais, inclusive dados sensíveis, que podem ser utilizados para a construção de perfis "indesejáveis", gerando rejeição social ou o surgimento de grupos de "excluídos".

Não se pode desconsiderar que a sociedade da informação está cada vez mais dependente da tecnologia e dos sistemas eletrônicos, o que merece atenção.

Vicente de Paula Maciel Júnior denomina o fenômeno de "escravidão em rede", diante de um roteiro de dominação e padronização de comportamento nunca antes possível na história da humanidade.

Para o autor, é uma "teia global que nos une a um só tempo em espaços diversos e tempo real e que supera fronteiras de língua, etnias, e que calmamente nos seduz e conduz a aparelhos cada vez mais amigáveis, tornando-se a tal ponto essenciais que não conseguimos mais prescindir deles” (MACIEL JÚNIOR; 2018).

Por tal razão, a questão afeta ao armazenamento e compartilhamento de dados pessoais passou a ser objeto de interesse dos Estados, o que fez surgir a necessidade de regulamentação da matéria.

Na Europa, veio a regulação pela "General Data Protection Regulation” (GDPR), aprovada pelo Parlamento europeu em 2016 e em vigor desde maio de 2018 (GDPR, 2018).

No Brasil, criou-se a Lei de n. 13.709/2018, mais conhecida como Lei Geral de Proteção de Dados Pessoais (LGPD). Segundo o artigo $1^{\circ}$ da LGPD, a lei tem o 
objetivo de proteger os direitos fundamentais de liberdade e de privacidade e o livre desenvolvimento da personalidade da pessoa natural (BRASIL, 2018).

Mesmo antes de vigorar a lei, prevalece a orientação no sentido de que devem ser vislumbradas restrições no tratamento de dados pessoais, bem como maior controle no uso desses.

Nessa perspectiva, é relevante a preocupação sobre a real abertura de dados aos fornecedores, como ainda se verifica nos dias de hoje.

Uma base eletrônica de dados, além de servir para consulta e informação sobre o consumidor, também pode ser utilizada para tentar impedir sua escolha racional e consciente, considerando o que ele realmente deseja.

Diante desse cenário, em que os consumidores encontram-se completamente vulneráveis, devemos nos ater à maneira de como deve ser realizada a oferta de bens e serviços aos consumidores, objetivando tentar traduzi-la, permitindo maior transparência, a fim de se recuperar o equilíbrio dessa relação, para que se possa estabelecer que o princípio de Justiça e Igualdade se sobreponham ao Sistema Capitalista predatório estabelecido.

A criação do Código de Defesa do Consumidor, por si só, já representa uma manifestação da sociedade contra a situação precária do consumidor, sendo este código uma tentativa de se moderar a desigualdade verificada nas relações sociais, buscando a igualdade substancial, favorecendo assim o convívio.

Para tanto, nota-se que o princípio da eticidade se encontra amparado na lei 8078/90, na medida em que esta procura salientar valores éticos no âmbito das relações de consumo. A proteção do consumidor contra publicidades abusivas ou enganosas, métodos coercitivos ou desleais, demonstra o destaque dado a esse caráter ético da lei (BRASIL, 1990).

Ademais, consoante já registrado, destaca-se no contexto da proteção do consumidor o reconhecimento da sua vulnerabilidade, prevista no inciso I do art. $4^{\mathrm{o}}$ do CDC que justifica a sua proteção pelo ordenamento jurídico (BRASIL, 1990).

Para explicar os instrumentos aplicáveis à tutela do consumidor, João Batista de Almeida, enfoca o princípio da isonomia. Assim ensina:

Os consumidores devem ser tratados de forma desigual pelo CDC e pela 
legislação em geral a fim de que consigam chegar à igualdade real. Nos termos do art. $5^{\circ}$ da Constituição Federal, todos são iguais perante a lei, entendendo-se daí que devem os desiguais ser tratados desigualmente na exata medida de suas desigualdades (ALMEIDA, 2000).

Na verdade, a utilização ou mesmo a gestão de dados de consumidores deve passar pela ideia de vigilância e segurança, sendo importante bem demarcar essa temática e as consequências jurídicas que podem advir diante da base de dados utilizada pelos programas de inteligência artificial.

Além disso, outra questão precisa ser verificada, qual seja, a privacidade do cidadão, sobretudo diante das constantes preocupações quanto à sua violação coma evolução da sociedade da informação ${ }^{17}$.

Nesse cenário, se de um lado há uma preocupação com a defesa da privacidade dos indivíduos, travando-se intensas discussões sobre vazamentos de dados, públicos e privados; de outro, há a necessidade de se verificar a existênciade interesse público relacionado àquele cidadão, relevante para a comunidade.

Por tal razão, é preciso esforço científico para delimitar este espaço virtual, conjecturando-se como necessária a oferta continuada de pesquisas para esclarecimento dessas questões, com a finalidade de assegurar, neste ambiente, os direitos e garantias fundamentais do povo, na tentativa de construção de uma realidade virtual democrática.

\section{CONCLUSÃO}

Como cediço, o advento do Código de Defesa do Consumidor consistiu em um avanço no tratamento das relações consumeristas. Todavia, diante da necessidade de proteção e defesa do consumidor, se mostra imperiosa a correta aplicação dos institutos previstos na Lei 8.078/90.

Em razão da situação vulnerável em que o consumidor se encontra na atualidade, o CDC traduz uma tentativa de se coibir os abusos cometidos com frequência pelos fornecedores e prestadores de serviços.

As relações de consumo enfrentam constantemente novos desafios, 
principalmente em um momento em que a tecnologia possibilita facilidades e, ao mesmo tempo, inovações na forma de se realizar negócios.

Vem aumentando o número de pessoas e dados disponíveis no meio eletrônico, sem qualquer segurança para o consumidor. Para proteger seus interesses, é preciso, além de uma legislação de proteção de dados pessoais, o estudo dos diversos instrumentos tecnológicos a permitir entender o real impacto dessa nova realidade.

A "sociedade da informação", ao influenciar as relações interpessoais, permitiu o surgimento de novas situações e relações jurídicas, diante do fluxo quase instantâneo de informação, capital e comunicação cultural.

Por isso, é fundamental que os operadores do direito avaliem se o momento tecnológico atualmente vivido apresenta interferências ou obstáculos à adequada tutela das relações consumeristas, principalmente quando baseadas na personalização de ofertas de produtos ou serviços ao consumidor.

Diante do exposto, não se pode olvidar que o Estado Democrático de Direito se fundamenta no exercício do poder pelo povo e na limitação deste poder pelas normas do ordenamento jurídico. Por tal razão, qualquer tipo de iniciativa (ou tecnologia) utilizada para desvirtuar este paradigma deve ser combatida.

\section{BIBLIOGRAFIA}

ALMEIDA, J. B. de. A Proteção Jurídica do Consumidor. $2^{\text {a }}$ ed., São Paulo, Saraiva, 2000 .

ANDRADE, André Gustavo. In Revista de Direito do Consumidor, nº 48, Ed.Revista dos Tribunais, outubro-dezembro, 2003.

BAUMAN, Z. Privacidade, sigilo, intimidade, vínculos humanos - e outras baixas colaterais da modernidade líquida. In. Danos colaterais: desigualdades sociais numa era global. Tradução de Carlos Alberto Medeiros. Rio de Janeiro: Zahar, 2013. BRANT, C. A. B. Marco Civil da Internet: comentários sobre a Lei 12.965/2014. Belo Horizonte: Editora D’Plácido, 2014.

BECKER, D. (2019). O acesso à informação jurídica on-line como medida de gatantia ao direito de acesso à justiça. Em V. N. Feigelson, Advocacia 4.0 (pp. 91- 102). São Paulo: Thomson Reuters.

BRASIL. Direito ao esquecimento. Brasília: Supremo Tribunal Federal, [2019]. 
Disponível em: <http://www.planalto.gov.br/ccivil_03/leis/19800.htm. Acesso em: 17. jul. 2019.

BULOS, Uadi Lammêgo. Constituição Federal Anotada. 4ª ed., Ed. Saraiva, São Paulo, 1998.

BENJAMIN, Antônio Herman V.; MARQUES, Cláudia Lima, BESSA, Leonardo

Roscoe. Manual de Direito do Consumidor. 5. ed. São Paulo: Ed. Revista dos Tribunais, 2014.

BLUM, Rita Peixoto Ferreira. O direito à privacidade e à proteção dos dados do consumidor. São Paulo: Almedina, 2018.

BRASIL. Constituição da República Federativa do Brasil de 1988, Brasília, DF, 1988.

Disponível em: http://www.planalto.gov.br/ccivil_03/Constituicao/Constituicao.htm. Acesso em: 04 mar 2021.

BRASIL, LEI No 10.406, DE 10 DE JANEIRO DE 2002. Institui o Código Civil, Brasília, DF, 2002. Disponível em:

http://www.planalto.gov.br/ccivil_03/leis/2002/L10406compilada.htm. Acesso em: 14 mar 2021.

BRASIL. LEI No 8.078, DE 11 DE SETEMBRO DE 1990. Dispõe sobre a proteção do consumidor e dá outras providências, Brasília, DF, 1990. Disponível em: http://www.planalto.gov.br/ccivil_03/leis/L8078compilado.htm. Acesso em: $12 \mathrm{fev}$ 2021.

BRASIL. LEI N ${ }^{\circ}$ 12.965, DE 23 DE ABRIL DE 2014. Estabelece princípios, garantias, direitos e deveres para o uso da Internet no Brasil, Brasília, DF, abril 2014. Disponível em: http://www.planalto.gov.br/ccivil_03/_ato2011-2014/2014/lei/112965.htm. Acesso em: 10 mar 2021.

BRASIL, LEI No 13.709, DE 14 DE AGOSTO DE 2018. Dispõe sobre a proteção de dados pessoais e altera a Lei $\mathrm{n}^{\circ}$ 12.965, de 23 de abril de 2014 (Marco Civil da Internet), Brasília, DF, 2018. Disponível em: http://www.planalto.gov.br/ccivil_03/_Ato20152018/2018/Lei/L13709.htm. Acesso em: 12 mar 2021.

CAPPELLETI, M.; GARTH, B. Acesso à justiça. Tradução e revisão de Ellen Gracie Northfleet. Porto Alegre: Sergio Antonio Fabris, 1988.

CARVALHO, Kildare Gonçalves. Direito constitucional. 16. ed. rev., atual. e ampl. Belo Horizonte: Del Rey, 2009. 
CASTELLS, M. A sociedade em rede. São Paulo: Paz e Terra, 2010.

CASTELLS, Manuel. A galáxia da Internet: reflexões sobre a Internet, os negócios e a sociedade. Rio de Janeiro: Jorge Zahar Editor, 2003.

COSTA JÚNIOR, Paulo José. O direito de estar só: tutela penal da intimidade. 4 ed.

São Paulo: Editora Revista dos Tribunais, 2007.

CONSALTER, Z. M. - Direito ao esquecimento: proteção da intimidade e ambiente virtual. Curitiba: Juruá Editora, 2017.

DEL NEGRI, A. O avesso do Estado. Belo Horizonte: Editora D`Plácido, 2018.

DOMINGOS, P. The master algorithm: how the quest for the ultimate machine learning

Will remake our world. New York: Basic Books, 2015.

DONATO, Maria Antonieta Zanardo, Proteção ao Consumidor: conceito e extensão,

São Paulo, Ed Revista dos Tribunais, 1993.

DONEDA, Danilo. A proteção de dados pessoais como direito fundamental. Revista

Espaço Jurídico 12/103. Joaçaba: Unoese, 2011.

FENOLL, J. N. Inteligencia artificial y proceso judicial, Madrid: Marcial Pons, 2018.

FREITAS, H. P. Eficiência da jurisdição: necessidade de sua (des)construção para efetivação do modelo constitucional de processo. Belo Horizonte: D'Plácido, 2019.

GAULIA, Cristina Tereza. In Revista de Direito do Consumidor, ${ }^{\circ}$ 40, Ed.Revista Dos Tribunais, outubro-dezembro, 2001.

GOMES, Orlando. Contratos. 26 ed. Rio de Janeiro: Editora Forense, 2008.

GONÇALVES, V. H. P. Cadeia de Custódia e o novo CPC. In: PARENTONI, L.;

GONTIJO, B. M.; LIMA, H. C. S. Direito, Tecnologia e Inovação. Belo Horizonte:

Editora D'Plácido, 2018. v. 1. p. 971-988.

LEAL, R. P. Estudos contemporâneos de Direito. In: SILVA, Cristian Kiefer da;

BIZZOTO, Daniel Augusto Arouca (org.). Belo Horizonte: Editora RTM, 2018. p. 5-26.

LÉVY, P. Cibercultura. Tradução e revisão de Carlos Irineu da Costa. São Paulo:

Editora 34, 2010.

MARQUES, Claudia Lima; “Comentários Contratos no Código de Defesa do

Consumidor", 4ª Ed., Revista dos Tribunais, 2002.

MARQUES, Claudia Lima; “Comentários Contratos no Código de Defesa do Consumidor", 2ª Ed., Revista dos Tribunais, 1999.

MENDES, G; COELHO, I. M.; BRANCO, P. G. G. Curso de Direito Constitucional. $1^{\mathrm{a}}$ ed., São Paulo: Saraiva, 2007. 
MONTEIRO, R. (14 de julho de 2018). Jota opinião e análise. Disponivel em: Jota: www.jota.info/opiniao-e-analise/colunas/agenda-da-privacidade-e-da-protecao-dedados/lgpd-analise-detalhada-14072018. Acesso em: 28 jan. 2019.

MUKAI, Toshio, Comentários ao Código de Proteção ao Consumidor; São Paulo, Saraiva, 1991.

NUNES, Luiz Antônio Rizzatto. Comentários ao Código de Defesa do Consumidor: direito material. São Paulo: Saraiva, 2000.

NUNES, Luiz Antônio Rizzatto. Curso de direito do consumidor. 7. ed. São Paulo: Saraiva, 2012

OLIVEIRA, Juarez de. In Comentários ao Comentários ao Código de Proteção ao Consumidor. São Paulo: Saraiva, 1991.

PLÁCIDO E SILVA, Vocabulário Jurídico, $3^{\text {a }}$ Edição, V.II, Rio de Janeiro, Forense, 1973.

PARO, J. P. (06 de junho de 2019). Jota opinião e análise. Disponivel em: www.jota.info/opiniao-e-analise/artigos/a-conformidade-do-poder-juriciario-a-leigeral-de-protecao-de-dados-06062019, Acesso em: 28 jul. 2019.

PINHEIRO, P. P. Direito Digital. São Paulo: Saraiva, 2007. RACANICCI, J. (27 de maio de 2019). jota.info. Disponível em: Jota:

www.jota.info/justica/cnj-normas-dados-pessoais-tribunais-27052019; Acesso em: 28 jun. 2019.

SIMÃO FILHO; SCHWARTZ, Direito, Tecnologia e Inovação. Big Data em tempos de Internet das coisas. Belo Horizonte: Editora D'Plácido, 2018. v. 1. p. 224-225

RADLOFF, Stephan Klaus, A inversão do Ônus da Prova no Código de Defesa do Consumidor, $1^{\text {a }}$ ed, Forense, Rio de Janeiro, 2002.

SARTORI, Ellen Carina Mattias. Privacidade e dados pessoais: a proteção contratual da personalidade do consumidor na internet. Revista de Direito Civil Contemporâneo, São Paulo, v. 3, n. 9, p. 49-104, out./dez. 2016.

SAAD, Eduardi Gabriel, Comentários ao Código de Defesa do Consumidor, São Paulo, $1^{\mathrm{a}}$ ed, LTR. 1991.

SOBRINHO, Mario de Camargo. Contrato de adesão e a necessidade de uma legislação específica. 1 ed. São Paulo: Editora Interlex, 2000.

TEFFÉ, Chiara Spadaccini de. MAGRANI. Eduardo. Artigo "Proposta para a criação da 
Autoridade Brasileira de Proteção aos Dados Pessoais. Disponível em:

https://itsrio.org/wp-content/uploads/2018/12/autoridade-protecao-de-dados.pdf. Acesso em: 27 jan 2021.

ROQUE, André. A tutela coletiva dos dados pessoais na lei geral de proteção de dados pessoais (LGPD). Disponível em: https://www.e-

publicacoes.uerj.br/index.php/redp/article/view/42138/30270. (2019) Revista Eletrônica de Direito Processual - REDP, Acesso em: 28 set. 2019.

Rio de Janeiro. Ano 13. Volume 20. Número 2. Maio a Agosto de 2019. (p. 01-19). 